\title{
KAUM AWAM MERASUL DI TENGAH DUNIA
}

\author{
Oleh: Albertus Magnus Rea
}

\begin{abstract}
Abstrak:
Artikel ini bertujuan untuk memberi pemahaman tentang peran awam dalam kerasulan Gereja. Kerasulan itu bukan hanya tugas imamat jabatan (hirarki) tetapi juga merupakan tugas awam (imamat terbaptis). Metode yang digunakan dalam penulisan ini adalah penelitian kepustakaan. Penulis meneliti sumber-sumber dari dokumen Gereja, buku-buku dan membuat analisis untuk mendapatkan hasil. Hasil yang diperoleh: Bunda Gereja mengajarkan bahwa kaum awam adalah objek pewartaan sekaligus merupakan subjek pewarta. Karena itu, keterlibatan kaum awam dalam kerasulan Gereja bukanlah pilihan tetapi imperatif teologis. Ini berarti semua orang yang telah dibaptis memiliki hak dan kewajiban yang sama untuk terlibat aktif menggarami dunia, sesuai dengan bidang keahliannya.
\end{abstract}

Kata-kata Kunci: Awam, Kerasulan, Imamat Tertabis, Imamat Terbaptis, Gereja.

\section{Pengantar}

$\mathrm{K}$

onsili Vatikan II (11 Oktober 1962-8 Desember 1965) telah membawa pembaharuan besar bagi Gereja. Konsili Vatikan II, mendorong Gereja membaharui dirinya. berakhir dengan Gereja di dalam Dunia (Gaudium et Spes). Dalam pembaharuan ini, (melalui dokumen dan dekrit hasil konsili) Gereja menekankan keterlibatan umat atau kaum awam dalam karya pastoral. Kaum awam harus terlibat penuh dalam karya Gereja. Kaum awam tidak menjadi penonton tetapi pelaku utama. Keterlibatan ini menampakkan wajah Gereja yang berwarna.

Gereja adalah milik seluruh umat beriman. Penegasan ini harus terus didengungkan agar pertama, seluruh umat sadar bahwa gereja bukanlah milik kaum klerus atau biarawan/ti, tetapi milik semua yang percaya kepada Kristus. Kedua, agar kaum awam terlibat dan berperan aktif dalam membangun gerejanya. Kaum awam turut serta bertanggung jawab terhadap hidup dan matinya Gereja. Gereja ada dalam tangan semua umat Allah.

\section{Dasar Keterlibatan Kaum Awam}

\subsection{Siapa Kaum Awam?}


Pada umumnya warga gereja dibagi menjadi dua golongan, yakni kaum tertahbis (imam) dan kaum awam. Kaum tertahbis, berkat rahmat tahbisan dan perutusan yang mereka terima dari para Uskup, diangkat untuk melayani Kristus Guru, Imam dan Raja. Mereka ikut menunaikan pelayanan-Nya, yang bagi Gereja merupakan upaya untuk tiada hentinya membangun dunia ini menjadi umat Allah, Tubuh Kristus dan Kenisah Roh Kudus (PO. art. 1). Tuhan mengangkat mereka (imam) untuk menjadi pelayan, yang dalam persekutuan dengan umat beriman mempunyai Kuasa Tahbisan suci untuk mempersembahkan Korban dan mengampuni dosa-dosa, dan demi nama Kristus secara resmi menunaikan tugas imamat bagi orang-orang (PO. art. 2).

Siapakah kaum awam? Secara singkat, kata awam kebanyakan dilihat dari pengertian negatif. Awam diartikan sebagai bukan imam, bukan klerus atau bukan ahli. Pendapat ini tidak sepenuhnya keliru. Oxford Advanced Learner's Dictionary of Current English, mendefinisikan berturut-turut kata Lay (awam) sebagai dia yang tidak termasuk kelompok klerus, tidak ahli atau tidak mahir dalam pengetahuan tentang suatu bidang, tidak memiliki kualifikasi profesional. Sementara kata kaum awam (layman/lay women) memiliki arti orang yang bukan ahli dalam pengetahun tentang hal tertentu; dan arti kedua adalah anggota Gereja yang bukan imam atau klerus.

Secara etimologis, kata awam berasal dari kata Yunani laos dengan kata sifatnya laikos yang berarti orang. Dalam Kitab Suci Perjanjian Lama, kata laos sering dipertentangkan dengan kata ta Eqnh yang berarti umat Allah. Kata ini membedakan arti umat Allah dari bangsa-bangsa (kafir) (bdk. Meo dan Beo, 2002: 42) Pembahasan selanjutnya akan menggunakan arti yang lebih positif, yang mana kaum awam diartikan sebagai anggota gereja. Kaum awam adalah semua orang beriman kristiani, kecuali mereka yang termasuk golongan imam atau status religius yang diakui dalam Gereja (LG. art. 31).

Kaum Awam ikut serta mengemban tugas imamat, kenabian dan rajawi Kristus. Kaum awam menunaikan bagian mereka dalam perutusan segenap Umat Allah dalam gereja dan di dunia. Mereka menjalankan kerasulan awam dengan kegiatan mereka untuk mewartakan Injil dan demi penyucian sesama, pun untuk meresapi dan menyempurnakan tata-dunia dengan semangat Injil, sehingga dalam tata-hidup itu kegiatan mereka merupakan kesaksian akan Kristus yang jelas, dan mengabdi kepada keselamatan umat manusia. Ciri khas status hidup awam yakni: hidup di tengah masyarakat dan urusan-urusan duniawi, maka mereka dipanggil oleh Allah, untuk dijiwai semangat kristiani, ibarat ragi, menunaikan kerasulan mereka di dunia (AA. art. 2).

\subsection{Kaum Awam dalam Misi Paulus}

Peran kaum awam dalam Perjanjian Baru sangat kelihatan. Peran ini dilakoni oleh orangorang yang menjadi teman Rasul Paulus dalam pelayanannya. Kisah Paulus sendiri sangat menarik. Ketika bertobat dari Saulus menjadi Paulus; dia bertemu dengan orang-orang (kaum 
awam) yang menolong dia dalam melaksanakan misinya. Adapun beberapa orang yang dapat dicatat sebagai rekan seperjalanan Paulus.

Pertama, Silas. Kisah Para Rasul mengisahkan pertemuan Paulus dan Silas. Pertemuan keduanya terjadi saat Paulus dan Barnabas hendak diutus ke Antiokia. Dalam misi ke Antiokia, para penatua memilih Yudas dan Silas untuk berangkat menemani Paulus dan Barnabas (Kis. 15:22). Setelah menyelesaikan misi di Antiokia, terjadi perselisihan antara Paulus dan Barnabas tentang Markus yang hendak dibawa serta Barnabas dalam misi selanjutnya. Paulus tidak menyetujui anjuran Barnabas karena Markus pernah bersama-sama dengan mereka tetapi meninggalkan mereka waktu misi di Pamfilia. Perselisihan ini membuat Paulus dan Barnabas berpisah. Barnabas mengajak Markus ke Siprus, sementara Paulus mengajak Silas untuk menjalankan misinya di Siria dan Kilikia (Kis. 15: 40).

Kedua, Timotius. Setelah pertemuannya dengan Silas, waktu Paulus ke Derbe dan Lista, ia bertemu dengan seorang murid bernama Timotius (Kis. 16:1). Timotius adalah orang yang sangat dikasihi Paulus sehingga dalam suratnya kepada Timotius, Paulus menyapanya dengan sebutan anakku yang kekasi (2 Tim. 1:1). Timotius sangat disayangi Paulus, sehingga Paulus mengingatkan orang-orang di Korintus untuk menjamu Timotius dengan sebaik-baiknya, jika ia datang kepada mereka; "Jika Timotius datang kepadamu, usahakanlah supaya ia berada di tengah-tengahmu tanpa takut, sebab ia mengerjakan pekerjaan Tuhan, sama seperti aku" (1 Kor. 16:10). Timotius bersama dengan Erastus diutus ke Makedonia (Kis. 19:22).

Ketiga, Titus. Titus merupakan salah satu teman seperjalanan Paulus. Titus ditinggalkan Paulus di Kreta. Tugas Titus di Kreta adalah "mengatur apa yang masih perlu diatur dan menetapkan penatua-penatua di setiap kota" (Tit. 1:5). Dalam suratnya kepada Titus, Paulus menyapanya sebagai anakku yang sah menurut iman kita bersama. Titus merupakan salah satu pelayan yang dikasihi Paulus.

Keempat, Filemon dan Onesimus (hamba Filemon). Dalam suratnya kepada Filemon diketahui bahwa Filemon adalah teman sekerja Paulus dan Timotius (Fil. 1:1). Salam Paulus ini menyiratkan bahwa Filemon (bersama Onesimus) telah menjadi rekan kerja Paulus dalam pewartaannya. Onesimus malah lebih lama bekerja sama dengan Paulus. Hal ini dapat diketahui ketika Paulus (sedang dalam penjara) hendak mengembalikan Onesimus kepada Filemon. Pesan Paulus, "terimalah dia seperti aku sendiri" (Fil. 1:17). Pesan Paulus ini tentu merujuk pada kebersamaannya dengan Onesimus. Bagi Paulus, Onesimus sangat berguna.

Selain kelima tokoh di atas, masih banyak "awam" yang menemani Paulus dalam perjalanan misinya. Beberapa "awam" dapat disebutkan di sini seperti Epafras (yang disebut sebagai pelayan Kristus yang setia, Kol. 1:7). Epafroditus (yang disebut sebagai saudara, teman sekerja dan seperjuangan Paulus, Flp. 2:25). Tikhikus (hamba yang setia dan pelayan dalam Tuhan, Kol. 4:7). Lukas (seorang tabib yang bukan Yahudi yang menemani Paulus dalam perjalanan kedua, Kol. 4:14-16). Markus (adalah kemenakan Barnabas yang ikut perjalanan Paulus yang pertama juga pernah bersama Paulus di penjara, Kol. 4:10). Trofimus (seorang 
Yunani yang bersama Paulus kembali ke Yerusem, Kis. 20:4; 21:29). Dan yang terakhir adalah Priskila dan Akwila yang adalah para sahabat Paulus yang menemani dan membantu Paulus secara spiritual maupun material dalam menunaikan tugas kerasulannya.

\subsection{Konsili Vatikan II}

Dalam Konsili Vatikan II, para Bapa Konsili menaruh perhatian yang besar terhadap keterlibatan awam dalam karya kerasulan Gereja. Apa yang dibicarakan Konsili Vatikan II mengenai kaum awam? Secara garis besar pertanyaan ini dapat dijawab: Konsili membicarakan tentang martabat kaum awam dalam Gereja, kekhasan panggilan kaum awam berkaitan dengan ciri keduniawiannya dan kerasulan kaum awam dalam Gereja dan masyarakat (bdk. LG. Bab IV). Bahkan secara khusus Konsili Vatikan II mengeluarkan dokumen Apostolicam Actuositatem (AA) yakni Dekrit tentang Kerasulan Awam. Dengan cara semacam itu, Konsili Vatikan II menegaskan kembali kedudukan kaum awam dalam Gereja yang lama sekali dilupakan, walaupun senyatanya peran kaum awam tidak pernah absen dalam kehidupan seluruh jemaat (bdk. AA. art. 1).

Penegasan doktriner semacam itu membawa semangat baru dan angin segar bagi kerasulan awam sehingga kaum awam tidak ragu-ragu memahami makna kerasulan mereka bagi Gereja. Konsili menegaskan bahwa panggilan untuk merasul bagi kaum awam mengalir dari martabat kaum awam yang merupakan bagian integral dari Gereja (Gitowiratmo, 2011: 58). Panggilan kristiani yang dihayati oleh seluruh Tubuh Kristus (Gereja) pada hakikatnya adalah panggilan untuk aktif merasul. Dengan demikian, kaum awam yang merupakan bagian dari Tubuh Kristus, bukanlah objek kerasulan (hierarkhi) Gereja tetapi mereka adalah subjeknya, pelaku aktif (AA. art. 2). Oleh karena itu, kaum awam bukanlah warga Gereja "kelas 2" dalam hal panggilan kristiani untuk merasul.

Untuk menjelaskan ajaran ini, konsili mengemukakan alasan teologisnya, misalnya dengan menegaskan bahwa berkat baptis, kaum awam memiliki martabat yang sama dengan semua anggota Gereja lainnya sebagai Umat Allah yang dalam Kristus tidak ada perbedaan (bdk. LG. art. 32 dan Gitowiratmo, 2011: 59). Selain itu kaum awam ikut mengambil bagian dalam tritugas Kristus (LG. art 34-36) dengan cara yang khas. Oleh sebab itu, kaum awam disebut sebagai pengambil bagian dalam karya keselamatan Allah yang berlangsung lewat perutusan Gereja. Konsili Vatikan II, membayangkan suatu kehidupan Gereja yang aktif dan dinamis. Di dalamnya, semua anggota baik itu awan dan hierarkhi berpartisipasi dalam gerak karya Gereja, walaupun masing-masing mempunyai cara yang khas (Gitowiratmo, 2011: 59).

\subsection{Apostolicam Actuositatem: Blue Print Kerasulan Awam}

Konsili Vatikan II, menghasilkan salah satu dekrit penting tentang awam yakni Apostolicam Actuositatem (AA)-(Kerasulan Awam). Dalam dekrit ini, dibahas secara khusus 
tentang keterlibatan kaum awam dalam karya kerasulannya. Dekrit ini memuat banyak hal tentang kerasulan awam. Pertama, panggilan kaum awam untuk merasul. Panggilan ini menegaskan keikutsertaan kaum awam dalam perutusan Gereja. "Gereja diciptakan untuk menyebarluaskan kerajaan kristus di mana-mana demi kemuliaan Allah Bapa, dan dengan demikian mengikutsertakan semua orang dalam penebusan yang membawa keselamatan, dan supaya melalui mereka seluruh dunia sungguh-sungguh diarahkan kepada Kristus" (AA art. 2). Panggilan untuk merasul ini didasarkan pada persatuan dengan Kristus yang diperoleh lewat pembaptisan.

Kedua, tujuan-tujuan yang harus dicapai. Tujuan kerasulan awam tidak hanya menyampaikan kabar tentang Kristus dan menyalurkan rahmat-Nya kepada umat manusia, melainkan juga untuk merasuki dan menyempurnakan tata dunia dengan semangat Injil (bdk. AA art. 5). Oleh karena itu, dalam melaksanakan perutusan Gereja, kaum awam menunaikan tugas kerasulannya mencakup bidang rohani dan duniawi. Ketiga, bidang-bidang kerasulan. Ada banyak bidang kerasulan yang dapat menjadi medan karya bagi kaum awam. Para bapa Konsili menganjurkan beberapa bidang karya kerasulan ini, yakni: jemaat-jemaat gerejawi, keluarga, kaum muda, lingkungan sosial, tata nasional dan internasional. Bagi Bapa Konsili, bidangbidang ini yang penting dan harus diperhatikan oleh kaum awam dalam karya kerasulannya (bdk. AA art. 9).

Keempat, berbagai cara merasul. Cara merasul yang dianjurkan adalah secara perorangan atau bergabung dalam paguyuban atau perserikatan. Bentuk kerasulan perorangan merupakan tanda paling sesuai dengan zaman kini. Lewat hidupnya yang bersumber pada iman, harapan dan cinta kasih, kaum awam memberi kesaksian bahwa Kristus hidup dan meraja di dalam umatNya (bdk. AA art. 16). Kerasulan perserikatan atau menyajikan tanda persekutuan dan kesatuan Gereja dalam kristus yang bersabda: "Sebab di mana dua atau tiga orang berkumpul dalam nama-Ku, disitu Aku hadir di tengah-tengah mereka" (Mat 18:20). Dalam persekutuan, mereka dapat merasul di lingkungan, paroki atau keuskupan (bdk. AA art. 18).

Kelima, tata tertib yang harus diindahkan. Kerasulan awam, yang dijalankan oleh umat beriman baik secara perorangan maupun secara kolektif, harus disatukan dalam kerasulan seluruh Gereja. Apa artinya? Artinya bahwa dalam karya kerasulan harus ada kerja sama antara awam dengan hierarkhi. Hierarkhi wajib mendukung kerasulan awam dengan menyediakan bantuan-bantuan rohani. Sedapat mungkin para imam menjadi Pembina atau pendamping bagi karya kerasulan ini. Oleh karena karya kerasulan ini berhubungan dengan keselamatan dunia, maka perlu kerja sama dengan umat Kristen dan umat beragama lain (bdk. AA art. 23-27).

Keenam, pembinaan untuk merasul. Pembinaan dalam karya kerasulan diperlukan agar karyanya sesuai dengan bermacam-macam situasi, orang-orang, dan tugas-tugas. "Kaum awam ikut serta menunaikan perutusan Gereja dengan cara mereka sendiri. Maka pembinaan mereka untuk kerasulan juga mendapat cirinya yang istimewa dari sifat sekuler (keduniaan) serta corak hidup rohani yang khas bagi status awam" (AA art. 29). Ketujuh, ajakan untuk merasul. "Konsili suci menyerukan agar kaum awam dengan suka rela, dan berjiwa besar, serta hati yang siap-sedia menanggapi sapaan Kristus, yang mengundang mereka, agar mengikuti dorongan Roh Kudus.” 


\section{Gereja (Kaum Awam) ada dalam Dunia}

Gereja ada dalam dunia dan kaum awam sebagai Gereja turut mengembara di dunia. Inilah kesadaran utama yang harus dibangun, agar umat beriman tidak lari meninggalkan dunia. Umat beriman harus masuk ke dalam dunia dan menjadi terang dan garam bagi dunia. Injil Yohanes mencatat dengan indah doa Yesus bagi murid-muridNya: "Aku tidak meminta, supaya Engkau mengambil mereka dari dunia, tetapi supaya Engkau melindungi mereka dari pada yang jahat... Sama seperti Engkau telah mengutus Aku ke dalam dunia, demikian pula Aku telah mengutus mereka ke dalam dunia;" (Yoh. 17:15.18). Dalam doa tersebut terlihat jelas bahwa Yesus bermaksud mengutus para murid ke dunia. Yesus tahu bahwa para muridNya bukan dari dunia, sehingga dunia membenci mereka; namun pengetahuan ini tidak membuat Yesus menghendaki para muridNya lari dari dunia. Bagi Yesus, dunia adalah tanah misi, tempat dimana kabar gembira harus diwartakan. Dunia adalah lahan di mana para murid sebagai Gereja dikehendaki oleh Allah untuk terus hadir dan bekerja.

Dalam dunia, Gereja hadir sebagai sakramen, yakni tanda dan sarana persatuan mesra dengan Allah dan kesatuan seluruh umat manusia. Gereja membawa keselamatan bagi dunia. Oleh karena itu, tugas Gereja di dunia adalah mewartakan keselamatan yang telah dibawa oleh Kristus. Tugas ini harus dijalankan mengingat Kristus sendirilah yang mendirikan Gereja. Pernyataan Yesus menanggapi pengakuan Petrus merupakan penegasan akan pendirian Gereja ini. "Engkau adalah Petrus dan di atas batu karang ini Aku akan mendirikan jemaatKu dan alam maut tidak akan menguasainya" (Mat. 16: 18).

Kaum awam, berkat rahmat pembaptisan ikut mengemban tugas imamat, kenabian dan rajawi Kristus, sesuai dengan kemampuan mereka melaksanakan perutusan segenap Umat kristiani dalam Gereja dan di dunia. Lumen Gentium menegaskan panggilan kaum awam, demikian:

Berdasarkan panggilan mereka yang khas, kaum awam wajib mencari kerajaan Allah, dengan mengurusi hal-hal yang fana dan mengaturnya seturut kehendak Allah. Mereka hidup dalam dunia, artinya: menjalankan segala macam tugas dan pekerjaan duniawi, dan berada ditengah kenyataan biasa hidup berkeluarga dan sosial. Hidup mereka kurang lebih terjalin dengan itu semua. Di situlah mereka dipanggil oleh Allah, untuk menunaikan tugas mereka sendiri dengan dijiwai semangat Injil, dan dengan demikian ibarat ragi membawa sumbangan mereka demi pengudusan dunia bagaikan dari dalam. Begitulah mereka memancarkan iman, harapan dan cinta kasih terutama dengan kesaksian hidup mereka, serta menampakkan Kristus kepada sesama. Jadi tugas mereka yang istimewa yakni: menyinari dan mengatur semua hal-hal fana, yang erat-erat melibatkan mereka, sedemikian rupa, sehingga itu semua selalu terlaksana dan berkembang menurut kehendak Kristus, demi kemiliaan Sang Pencipta dan Penebus. (LG. art. 31).

Apa yang dikatakan para uskup ini menggambarkan bahwa dunia merupakan lahan yang sangat tepat bagi kaum awam untuk menjalankan tugasnya sebagai murid Kristus. Mereka ada dan hidup dalam dunia, berkarya dalam dunia sesuai dengan panggilannya. Dalam karyanya kaum awam diharapkan untuk memberikan kesaksian tentang iman, harapan dan cinta yang 
Allah berikan padanya. Singkatnya, tugas kaum awam adalah menjadi rasul-rasul yang mewartakan karya keselamatan Kristus kepada dunia. Melalui mereka, Gereja Kristus dihadirkan di dalam berbagai sektor kehidupan dunia sebagai tanda dan sumber harapan dan cintakasih.

\section{Peranan Kaum Awam}

Kaum awam diharapkan terlibat aktif dalam berbagai karya kerasulan Gereja. Hal penting yang perlu diingat bahwa posisi dan peran kaum awam langsung berkaitan erat dengan misi Gereja. Misi Gereja yang ada dalam dunia, harus bersinggungan dengan kaum awam yang menjadi penghuni dunia. Pertanyaan besar kini, apakah kaum awam telah menjalankan peranannya dengan baik? Apostolicam Actuositatem sebagai cetak biru kerasulan awam menegaskan peranan kerasulan awam adalah mewartakan Injil dan menyucikan umat manusia (bdk AA. art. 6).

\subsection{Mewartakan Injil}

Perjalanan sejarah Gereja Katolik menggambarkan adanya kecenderungan memberikan peran sentral dan autoritatif pada hierarkhi. Kecenderungan ini makin memudar seiring perjalanan Gereja yang kemudian mengarahkan bukan hanya pada imamat jabatan tetapi juga pada sisi imamat baptisan. Setiap orang beriman yang telah dibaptis memiliki martabat imami, rajawi dan kenabian. Maka semua orang beriman, entah imam, entah awam, memiliki panggilan yang sama, namun dalam peran dan posisi berbeda tanpa yang satu melebihi dan menguasai yang lain, masing-masing mendapatkan terang bimbingan dari Roh yang satu dan sama. Karenanya, aspek kolegialitas dan partisipatif semakin perlu mendapatkan tekanan (Cahyadi, 2013: 103). Malahan dikatakan oleh Paus Yohanes Paulus II dalam seruannya Christifideles Laici art. 27, bahwa tanpa peran aktif kaum awam, tugas pelayanan pastoral kaum imam tidak akan dapat diwujudkan.

Kabar gembira (Injil) yang diwartakan tidak dapat dilepaskan dari pribadi Yesus Kristus. Yesus Kristuslah yang memberikan tugas perutusan kepada para rasul. "Karena itu pergilah, jadikanlah semua bangsa muridKu dan baptislah mereka dalam nama Bapa dan Anak dan Roh Kudus, dan ajarlah mereka melakukan segala sesuatu yang telah Kuperintahkan kepadamu" (Mat. 28:19-20). Perintah Yesus ini menggarisbawahi diriNya sebagai pusat pewartaan. Oleh karena itu, Yesuslah yang senantiasa harus diwartakan kepada siapapun, dengan maksud agar Ia dicintai dan diimani. Dia dapat dikenal, dicintai dan diimani kalau ada orang yang diutus untuk mewartakanNya (Prasetya, 2011:28).

Mewartakan Injil berarti mewartakan Kristus kepada dunia dengan kata-kata (verbal) maupun dengan perbuatan (nonverbal), dan untuk menyalurkan rahmatNya (bdk. AA art.6). Pewartaan dengan kata-kata menjadi penting bagi yang tidak atau belum beriman untuk mengantar mereka kepada iman. Sedangkan bagi mereka yang sudah beriman, pewartaan itu berfungsi untuk mengajar dan meneguhkan, serta mengajak dan menyemangati mereka untuk 
hidup dengan semangat yang lebih besar (Poerwanto, 2013:21). Di zaman yang semakin modern kini, pewartaan tidak cukup hanya dengan kata-kata. Hidup kaum beriman hendaknya menjadi pewartaan nyata kasih Allah yang menyapa manusia.

Pernyataan apostolik Ecclesia in Asia art. 45 menunjukkan bagaimana keterlibatan kaum awam hendaknya diwujudkan. Dikatakan di dalamnya bahwa kaum awam adalah pewarta Injil di tengah tantangan dewasa ini sehingga mereka diharapkan menyatakan kesaksian bukan sekedar dengan pertimbangan kebijaksanaan manusiawi dan efisiensi, namun terlebih dengan hati yang senantiasa diperbarui dan diperkuat oleh kebenaran Kristus. Dengan demikian, kesaksian iman mereka mendapatkan peran unik terlebih bagi perjuangan keadilan (Cahyadi, 2013: 104). Memang gereja profetik akan semakin hadir nyata jika kaum awam secara aktif terlibat dan berperan dalam pewartaan injil.

\subsection{Menyucikan Umat Manusia}

Bila dimengerti bahwa awam adalah bagian integral Gereja, maka karya kerasulan awam bersatu erat dengan karya kerasulan Gereja. Dalam Gereja hanya ada satu perutusan, yakni menjadi saksi bagi misteri rencana penyelamatan Allah demi penebusan manusia. Kerasulan awam bukanlah kerasulan yang dilakukan berdasarkan hobi tetapi muncul dari kodrat panggilannya. Panggilan yang diperolehnya lewat rahmat pembaptisan.

Berkaitan dengan menyucikan umat manusia, AA. art. 6 mengingatkan kaum awam demikian "Pada zaman kita sekarang muncullah masalah-masalah baru, dan beredarlah kesesatan-kesesatan amat gawat, yang berusaha menghancurkan sama sekali agama, tatakesusilaan dan masyarakat manusia sendiri." Peringatan ini menggarisbawahi bahwa dunia yang menjadi medan kerasulan menghadapi masalah dan tantangan itu. Umat manusia yang hidup didalamnya telah terkontaminasi dengan hal-hal di atas. Dengan demikian, penyucian umat manusia ini lebih berhubungan dengan penyucian terhadap masalah-masalah yang dihadapi oleh umat manusia zaman ini.

Melihat masalah yang dihadapi manusia zaman ini maka dapat dikatakan bahwa menyucikan umat manusia dalam zaman seperti ini, merupakan tugas yang berat sekaligus menantang. Berat karena kerasulan akan berhadapan dengan masalah yang de facto sangat kompleks, sementara menantang karena kaum awam dituntut untuk mencari cara-cara kerasulan yang tepat untuk menyelesaikan kompleksitas masalah dunia. Oleh karena itu, "Konsili suci ini dengan tulus hati mengajak kaum awam, masing-masing menurut bakat-pembawaan dan pendidikan pengetahuannya, supaya mereka - menurut maksud Gereja - lebih bersungguhsungguh lagi menjalankan peran mereka dalam menggali dan membela azas-azas kristiani, serta dalam menerapkannya dengan cermat pada soal-soal zaman sekarang" (AA. art. 6).

Bagaimana tugas menyucikan umat manusia dijalankan? Pertama-tama yang harus dilakukan adalah memandang dengan adil dan positif terhadap dunia. Dunia bukanlah tempat yang asing bagi pewartaan. Kerasulan kaum awam harus menjadi garam dan terang bagi dunia. Kerasulan ini harus meresapi dunia dengan cita rasa Injil. Dalam kaitan dengan hal ini, Konsili 
mengingatkan bahwa Allah memiliki rencana mengenai dunia ini yakni agar umat manusia seiasekata membaharui dan terus-menerus menyempurnakan tata-dunia. (bdk. AA. art.7). Menjadi garam dan terang untuk meresapi dunia dengan semangat Injil adalah tugas kaum awam sebagai anggota Gereja dan warga masyarakat (bdk. Meo dan Beo, 2002: 84). Dengan demikian, menyucikan umat manusia berarti membawa umat manusia kepada Allah.

\section{Penutup}

Karya kerasulan Gereja, bukanlah ranah privat hirarki, melainkan ranah semua umat beriman (bdk. LG. art. 10). Oleh karena itu, penentuan kebijakan pastoral tidak bisa bersandar hanya pada pemahaman filosofis-teologis dan penggunaan kewenangan tahbisan. Karya kerasulan harus ditinjau dari berbagai aspek, baik manusiawi maupun ilahi. Karya kerasulan memerlukan kerjasama atau kolaborasi antar bidang serta kerjasama awam dan religius. Semakin banyak orang yang terlibat, baik sebagai subyek pelaku pastoral maupun sebagai obyek yang dituju, maka semakin banyak waktu dan tenaga yang diperlukan. Harapannya bahwa karya kerasulan semakin mendekati kebutuhan umat Allah dan pada saat yang sama menjawabi apa yang menjadi kehendak Allah bagi umat-Nya.

Keterlibatan kaum awam dalam karya kerasulan ini bukanlah suatu pilihan, tetapi panggilan. Panggilan ini menentukan terlaksana tidaknya misi Gereja sebagai penerus misi Yesus Kristus kepada segala bangsa di dunia. Pelaksanaan panggilan tersebut bukan semata-mata tanggung jawab kaum awam. Hirarki, yang berkarya di bidang rohani, perlu membenahi diri pula agar lebih mampu mendampingi kaum awam sesuai dengan panggilannya. Menjaga hidup rohani kaum awam dalam keterlibatan mereka di dunia.

Kaum berjubah hendaknya memaknai keterlibatan sebagai tugas yang harus diemban berkaitan dengan imamat jabatan yang dimilikinya. Kesadaran ini harus terus dipupuk agar kaum awam tidak merasa menjadi orang nomor dua dalam melaksanakan karya kerasulan Gereja. Kaum awam adalah objek dan subjek dalam karya kerasulan. Mewartakan kabar gembira dan menyucikan umat manusia merupakan tugas kaum awam dalam kerjasamanya dengan hierarkhi.

\section{Kepustakaan:}

\section{Dokumen Gereja}

R. Hardawiryana. Dokumen Konsili Vatikan II. Jakarta: Dokumentasi dan Penerangan KWI, 1992.

Susanto, Harry (Penterj.). Kompendium Katekismus Gereja Katolik. Yogyakarta: Kanisius, 2013. LBI, Alkitab Deuterokanonika

\section{Buku-Buku}

Cahyadi, Krispurwana. Pastoral Gereja. Yogyakarta: Kanisius, 2013. 
Gitowiratmo, St. Seputar Dewan Paroki. Yogyakarta: Kanisius, 2011.

Komkat KAS. Mengikuti Yesus Kristus 2. Yogyakarta: Kanisius, 2012.

Meo, Ansel dan Beo, Kons. Memahami Awam dan Kerasulannya. Ende: Nusa Indah, 2002.

Poerwanto, YR. Edy. OMK Alergi Politik? No Way?! Yogyakarta: Kanisius, 2013.

Prasetya, L. Menjadi Katekis, Siapa Takut?! Yogyakarta:Kanisius, 2011.

Sinaga, Anicetus B. Awam Triniter-Sapta Karya Pelayan Awam. Jakarta: Obor, 1993.

$* * *$ 